\title{
Management of Pain In Erosive Lichenplanus using Low Level Lasertherapy (LLLT): A Report of Two Cases
}

\author{
S.V. Suman ${ }^{1}$, Nagajyothi Peta ${ }^{2}$, Vijaykumar Bokkasam ${ }^{3}$, Sathish Babu. D4, Sunil. Y.V ${ }^{5}$, Yamini Puchalapalli ${ }^{6}$ \\ ${ }^{1}$ Professor, Department of Oral Medicine and Radiology, ${ }^{2}$ Post Graduate, Department of Oral Medicine and Radiology, \\ ${ }^{3}$ Professor and HOD, Department of Oral Medicine and Radiology, ${ }^{4}$ Reader, Department of Oral Medicine and Radiology, \\ ${ }^{5}$ Post Graduate, Department of Oral Medicine and Radiology, ${ }^{6}$ Post Graduate, Department of Oral Medicine and Radiology, \\ CKS Theja Dental College, Renigunta Road, Tirupathi, India
}

Corresponding author: Nagajyothi Peta, Post Graduate, Department of Oral Medicine and Radiology, CKS Theja Dental College, Renigunta Road, Tirupathi, India

DOI: http://dx.doi.org/10.21276/ijcmsr.2019.4.3.49

How to cite this article: S.V. Suman, Nagajyothi Peta, Vijaykumar Bokkasam, Sathish Babu. D, Sunil. Y.V, Yamini Puchalapalli. Management of pain in erosive lichenplanus using low level lasertherapy (LLLT): a report of two cases. International Journal of Contemporary Medicine Surgery and Radiology. 2019;4(3):C223-C226.

\section{A B S T R A C T}

Introduction: OLP is a mucocutaneous disease with uncertain etiology. Many treatment modalities like topical /systemic corticosteroids, immunomodulators are used to treat symptoms but refractory cases incidence is increasing, recently treatment with LASERS made a proper path for treatment of such cases. Lasers used in previous studies to treat various types of lichen planus are CO2, ND:YAG and some wavelength of diode lasers. In our study we use a wavelength of 980nm diode lasers for treatment of erosive lichen planus. Symptoms were measured and analysed by VAS scale and clinical assessment. Case report: This article aims to report of two cases of erosive lichen planus of oral cavity in a 68 year old female and in 28 year old male with emphasis on histopathology.

Conclusion: This study showed successful use of $980 \mathrm{~nm}$ diode laser for treating OLP with complete remission of symptoms rapidly with no adverse effects.

Keywords: Erosive Lichen Planus, Topical Corticosteroids, Low Level Laser Therapy.

\section{INTRODUCTION}

Lichen planus is considered as an autoimmune chronic mucocutaneous disease which can affect skin, scalp, genital mucosa, and oral cavity. In oral cavity the common sites are buccal mucosa, tongue and gingiva. Oral lichen planus is diagnosed more commonly in middle aged women with female to male ratio $1.5: 1 .^{2}$ Skin lesions in lichen planus usually resolve with in 1 or 2 years, where as in oral lichen planus it may persists for 20 years or more. ${ }^{3}$ In oral cavity keratotic (white) and Non keratotic (atropic/ulcerative/ erosive) forms has been described. ${ }^{4}$ keratotic lesions are usually asymptomatic and need no therapy, while red lesions are to be treated for symptoms like pain and burning sensation as well as their malignant potential.5,6 Many treatment modalities are in use but local corticosteroids remain the main treatment with promising outcome in remission of pain and burning sensation., ${ }^{7,8}$ The drug should be used intermittently and systemic therapy may be required. Adverse effects include mucosal atrophy, candidiasis, adrenal suppression, gastrointestinal upset, hypertension, hyperglycemia. ${ }^{9,10}$ However, in some patients symptoms may not be relieved and reccurence rate is high. Therefore effective treatment like LLLT has been introduced for treating erosive oral lichen planus with minimal side effects. ${ }^{11,12}$ Effects of LLLT on tissues includes vasodilatation, enhanced blood flow, lymph drainage, neutrophils, fibroblast activation and pain stimulation threshold. Other effects are aggregation of prostaglandins(PGE2), immunoglobulins and lymphokines, $\beta$-endorphins in tissues resulting in reduction of inflammation, immuneresponse and pain. ${ }^{13,14}$ Several LLLTs are used to treat OLP in the range of $600-1100 \mathrm{~nm}$, with various intensities, power, duration and number of sessions. This article presents three cases of erosive oral lichen planus treated via $980 \mathrm{~nm}$ diode laser.

\section{CASE REPORTS}

Case 1: A 62 years old female patient with a chief complaint of pain and burning sensation on the left buccal mucosa and right buccal mucosa near 46, 47, 48 region referred to the dental office. The patient is known hypertensive since one year and under medication. On examination of oral cavity erosive lesion with white keratotic striae (wickham's striae) was found on the left buccal mucosa, also mild to moderate gingivitis. Xerostomia due to lack of sufficient saliva was obvious. These signs and symptoms are suggestive that the lesion might be erosive oral lichen planus. Conventional hematological and biochemical tests were performed and no abnormality was detected, therefore incisional biopsy was performed under local anaesthesia from the left buccal mucosa and two samples with an approximate size of 

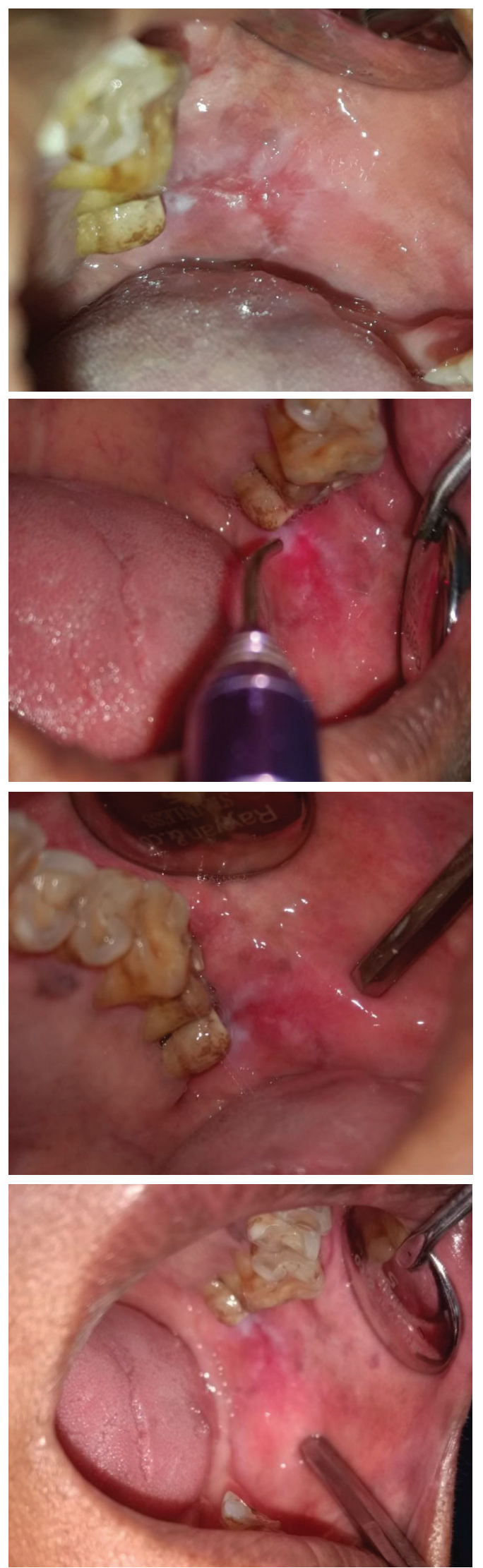

Case-1: Before treatment; During LLLT(low level laser therapy); After laser treatment; Follow up visits

$4 \times 3 \times 3 \mathrm{~mm}$ were obtained. The histopathological investigation confirmed the diagnosis of OLP. The patient was prescribed triamcinolone ointment and chlorhexidine. After two
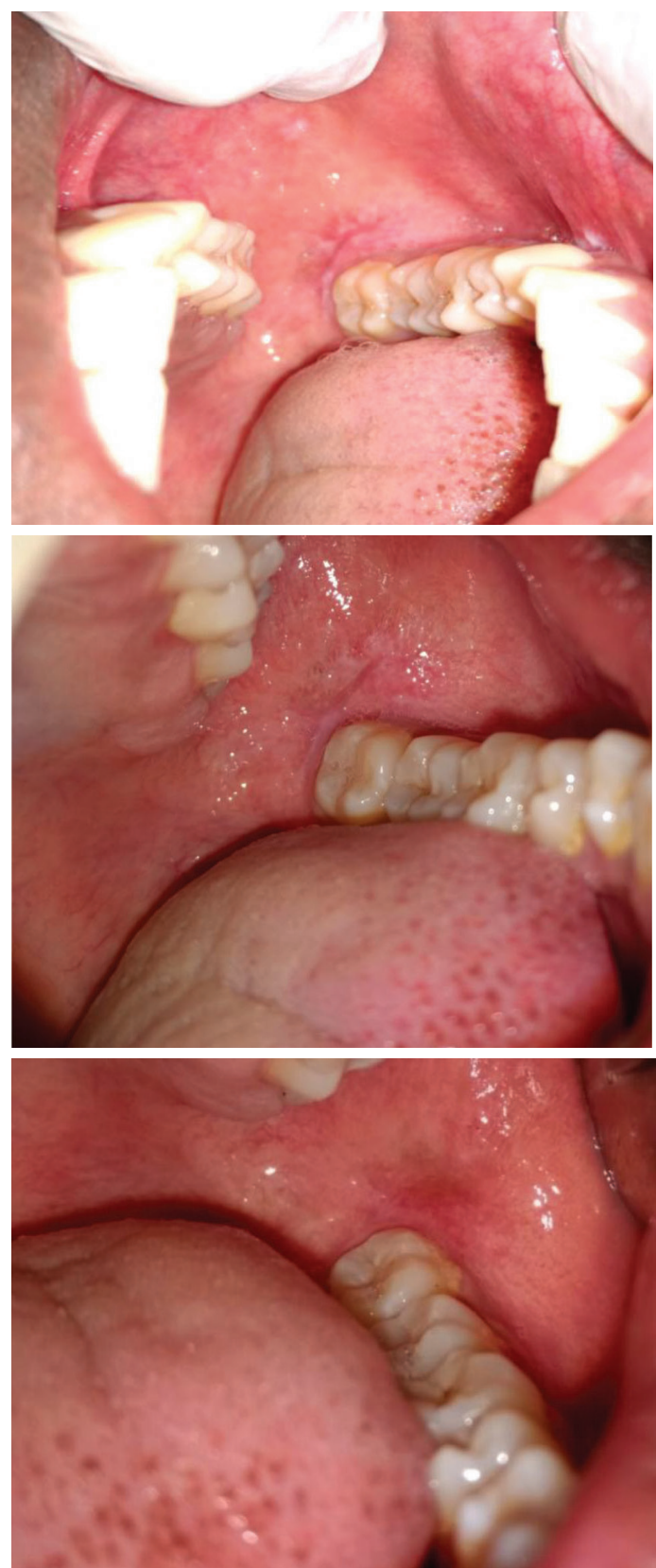

Case-2: Before treatment; after laser therapy; after 6 months follow up

months of treatment, no recovery was seen in signs and symptoms. So the patient was treated with laser therapy. The patient was asked to stop taking drugs to evaluate the efficacy of laser therapy. Firstly the 980nm diode laser (ZOLAR) was used for photobiomodulation(PBM), 0.3W, 6J, 20sec, continuous wavelength $(\mathrm{CW})$ mode, energy density of $6 \mathrm{~J} /$ $\mathrm{cm}^{2}, 2 \mathrm{~mm}$ away from the lesion, after 4 sessions and with complete remission of pain and slight decrease of burning sensation. The setting changed to $0.2 \mathrm{~W}, 4 \mathrm{~J}, 20 \mathrm{sec}, \mathrm{CW}, 2 \mathrm{~mm}$ away from the lesion, energy density of $4 \mathrm{~J} / \mathrm{cm}^{2}$, then the treatment continued upto 8 sessions ( 3 sessions in a week) as a result, the patient symptoms were relieved, no pain and burning sensation also the saliva showed significant increase. The visual analogue scale (VAS) was used to measure the efficacy of the treatment and severity of the symptoms; the score of this scale varies from 0 (no pain) to 10 (maximum 
pain).

As a result of laser therapy pain and burning sensation were treated.

\begin{tabular}{|l|c|c|c|}
\hline & $\begin{array}{c}\text { Before } \\
\text { treatment }\end{array}$ & $\begin{array}{c}\text { After 4 ses- } \\
\text { sions (1-8 days) }\end{array}$ & $\begin{array}{c}\text { After 8 ses- } \\
\text { sions (16 days) }\end{array}$ \\
\hline VAS & 8 & 4 & 0 \\
\hline
\end{tabular}

The patient was recalled for follow up after one month, three months, and six months after laser therapy showed no sings of recurrence. The patient was not under medication during this period.

Case 2: A 28 years old male patient with a chief complaint of pain and burning sensation on the left retromolar area was referred to C.K.S theja institute of dental sciences and research, tirupati. On examination of oral cavity the lesion was erosive intersparsed with white striae (wickham's striae). These signs and symptoms were suggestive of erosive lichen planus. In conventional and biochemical investigations no abnormality detected. Therefore incisional biopsy was performed under local anesthesia. The histopathological investigation confirmed the diagnosis of OLP. The patient was prescribed triamcinolone ointment and chlorhexidine. After 2 months of treatment, no recovery was seen in signs and symptoms. So the patient was treated with laser therapy. The patient was asked to stop taking drugs to evaluate the efficacy of laser therapy. Firstly the 980nm diode laser (ZOLAR) was used for photobiomodulation (PBM), 0.3W, 6J, 20sec, continuous mode (CW) mode, energy density of $6 \mathrm{~J} / \mathrm{cm}^{2}, 2 \mathrm{~mm}$ away from the lesion, after 4 sessions and with complete remission of pain and slight decrease of burning sensation. The setting changed to $0.2 \mathrm{~W}, 4 \mathrm{~J}, 20 \mathrm{sec}, \mathrm{CW}$, $2 \mathrm{~mm}$ away from the lesion, energy density of $4 \mathrm{~J} / \mathrm{cm}^{2}$ then the treatment continued upto 6 sessions ( 3 sessions a week). As a result, the patient symptoms were relieved, (no pain and burning sensation).

\begin{tabular}{|c|c|c|c|}
\hline & $\begin{array}{c}\text { Before } \\
\text { treatment }\end{array}$ & $\begin{array}{c}\text { After 4 sessions } \\
\text { (1-8 days) }\end{array}$ & $\begin{array}{c}\text { After 6 sessions } \\
\text { (12 days) }\end{array}$ \\
\hline VAS & 5 & 2 & 0 \\
\hline
\end{tabular}

The patient was recalled for follow up after a month, 3 months, 6 months after laser therapy showed no signs of recurrence. The patient was not under medication during this period.

\section{DISCUSSION}

OLP is a potentially malignant disorder of oral cavity which causes pain and burning sensation. Till date corticosteroids are the first line of treatment which can help to reduce the symptoms but can cause side-effects and also can't be used in patients with systemic diseases. So in recent times LLLT has been introduced specifically for mucocutaneous diseases such as OLP (14-16). Early and traditional use of laser with $\mathrm{CO} 2$ has acceptable clinical results. Symptoms were relieved immediately and long term follow up showed decreased recurrence rate (17). Another study used ND:YAG and $\mathrm{CO} 2$ laser simultaneously was proved to be effective with advantages being conservative, site specific and minimally invasive.(18).

In the study by kollner et al., 75 to $150 \mathrm{~mJ} / \mathrm{cm}^{2}$ power of 308 $\mathrm{nm}$ excimer laser were emitted to OLP lesions three times a week, up to 32 sessions. One patient showed remission after 12 sessions with no signs of relapse on the four months follow up period. Another patient had relative remission after 9 sessions, but with relapse one month later. Four patients were relative and 2 patients were absolute non-responders. ${ }^{10}$ On the other hand $308 \mathrm{~nm}$ excimer laser emits ultraviolet $\mathrm{B}$ (UV-B) rays with a tissue penetration of less than $0.3 \mathrm{~mm}$. The UV-B excimer laser is potentially carcinogen. Besides, erythema, erosion and soreness are probable side effects of its use. ${ }^{10}$

In the study by jajarm et al. 630nm diode laser was used for LLLT, the results showed LLLT was as effective as topical corticosteroids with fewer side -effects. Pain score, lesion severity and appearance were reduced in both groups. Based on the findings mentioned, LLLT could be an appropriate alternative for treatment of erosive-atrophic OLP. ${ }^{14} 630 \mathrm{~nm}$ lasers penetrates tissue several millimeters deep reduce inflammation, pain relief and ulcer healing effects. ${ }^{14}$

Soleiman et al. evaluated the efficacy of $980 \mathrm{~nm}$ diode laser in the treatment of OLP, the results were remarkable, no serious side effects was reported and recurrence was recorded in 3 out of 25 patients only. So the method was suggested as an appropriate alternative for local and systemic treatment using drugs. ${ }^{19}$

In our study using $980 \mathrm{~nm}$ diode laser was aimed to decrease pain and burning sensation. In Case 1 after 8 days ( 4 sessions) we have observed marked regression of symptoms (VAS score 8 to 4 ) and after 16 days (8 sessions) we have observed complete remission of pain, burning sensation, ulcer healing (VAS-0). In CASE 2 after 8 days (4 sessions) we have observed marked regression of symptoms (VAS score 5 to 2 ) and after 12 days (6 sessions) we have observed complete regression of symptoms (VAS -O).

The results was satisfactory. At 48 hours follow up marked remission of pain and burning sensation. After 1 week follow up, reduction in size was obvious and after 2 weeks follow up lesion disappeared completely. On a month, 3 months, 6 months follow up no signs of recurrence was seen.

\section{CONCLUSION}

This study showed successful use of 980nm diode laser for treating OLP with complete remission of symptoms rapidly with no adverse effects. Further investigations with large number of patients and longer follow up are needed to approve this method as a standard clinical treatment.

\section{REFERENCES}

1. Ismail SB, Kumar SK, Zain RB. Oral lichen planus and lichenoid reactions: etiopathogenesis, diagnosis, management and malligant transformation. J oral sci. 2007;49 (2): 89-106.

2. Mollaoglu N. Oral lichen planus; a review. Br J Oral Maxillofac surg. 2000; 38 (4):370-377.

3. Eisenberg E. Oral lichen planus: a benign lesion. J Oral Maxillofac surg 2000;58(11):1278-1285.

4. Greenberg M, Glick M, Burket's Oral medicine diagnosis and treatment. $11^{\text {th }}$ ed, Ontario:BC Decker Inc; 2008: 89-96.

5. Sharma S, Saimbi CS, Koirala B. Erosive lichen planus and its management: a case series. JNMA J Nepal Med Assoc 2008; 47:86-90. 
6. Epstein JB, Wan LS, Gorsky M, Zhang L. Oral lichen planus: progress in understanding its malignant potensial and implications for clinical management. Oral surg Oral Med Oral pathol Oral Radiol Endod 2003;96(3): 32-37.

7. Conrotto D, Carbone M, Carrozzo M, Arduino P, Broccoletti R, Pentenero M, et al. Ciclosporin vs Cllobetasol in the topical management of atophic and erosive oral lichen planus: a double -blind, randomized controlled trail. Br J Dermatol 2006;154(2):139-145.

8. Thongprasom K, Luangjarmekorn L, Sererat T, Taweesap W, Relative efficacy of flucinolone acetonide compared with triamcinolone acetonide in treatment of oral lichen planus. J Oral Pathol Med 1992; 21(5):456 $-458$.

9. Passeron T, Zakaria W, Ostovari N, Montoux F, Lacour JP, Ortonne JP. Treatment of erosive lichen planus by 308nm excimer laser.Lasers Surg Med 2004;34 (4):205.

10. Kollner K, Wimmershoff M, Landthaler M, Holen leutner U. Treatment of oral lichen planus with the 308 UVB excimer laser - early preliminary results in eight patients. Lasers Surg Med 2003; 33(3): 158-160.

11. Shirani AM, Gut knecht N, Taghizadeh M, Mir M. Low level laser therapy and myofacial pain dysfunction syndrome: a randomized controlled clinical trial. Lasers Med Sci 2009;24(1):715 -720.

12. Cavalcanti TM, Almeida -Barros RQ, Catao $M H$, Feitosa AP, Lins RD. knowledge of the physical properties and interaction of laser with biological tissue in dentistry. An Bras Dermatol 2011; 86 (3): 955-960.

13. Derikvand N, Ghasemi SS, Moharami M, Shafiei E, Chiniforush N. Maanagement of oral lichen planus by 980nm diode laser. J Laser Med Sci 2017; 8 (3):150154.

14. Jajaram HH, Falaki F, Mahdavi O. A comparative study of low intensity laser versus topical corticosteroids in the treatment of erosive - atrophic oral lichen planus. Photomed Laser Surg 2011;29 (3):421-425.

15. Walker MD, Rumpf S, Baxter GD, Hirst DG, Lowe AS. Effect of low -intensity laser irradiation (660nm) on a radiation -impaired wound healing model in murine skin. Lasers Surg Med 2000;26 (4):41-47.

16. Lagan KM, Clements BA, Mc Donough S, Baxter GD. Low intensity laser therapy $(830 \mathrm{~nm})$ in the management of minor postsurgical wounds: a controlled clinical study. Lasers Surg Med 2001;28 (5):27-32.

17. Loh $\mathrm{H}, \mathrm{A}$ clinical investigation of management of oral lichen planus with CO2 laser surgery. J Clin Laser Med Surg. 1992; 10 (6):445-449.

18. White J, Chaudhry S, Kudler J, Sekandari N, Schoelch M, Silverman S Jr. Nd:YAG and CO2 laser therapy of oral mucosal lesions. J Clin Laser Med Surg. 1998; 16 (6):299-304.

19. Soliman M, E1 Kharbotly A, Saafan A. Management of oral lichen planus using diode laser $(980 \mathrm{~nm})$; a clinical study. Egyptian Dermatol Online J. 2005; 1(3):1-12.

Source of Support: Nil; Conflict of Interest: None

Submitted: 09-06-2019; Accepted: 13-08-2019; Published online: 21-09-2019 